Vol 1 Issue 3 (2020)

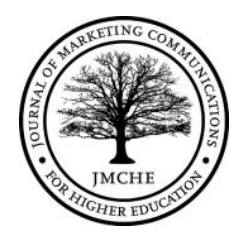

\title{
It Only Works if it All Works: An analysis of integrated marketing communications and its application for enrollment management marketers
}

\author{
Christopher Huebner, MMC, M.E. Cyberwoven
}

\section{Introduction}

With the publishing of Demographics and the Demand for Higher Education, author Nathan D. Graw (2018) produced a bleak forecast for traditional institutions of higher education. ${ }^{1}$ Patterns of migration, fertility rates, and immigration project a decrease in college-aged populations and instability in geographic trends. These dramatic changes are starting to be felt within the industry and will continue to present enrollment challenges. And while the industry has placed a renewed interest in marketing, much of the literature is specific to branding, reputation/prestige and the translation of the student experience to marketing outcomes. In fact, Chapleo and O'Sullivan, in the Journal of Marketing for Higher Education, applaud the recent application of broad marketing concepts such as "place marketing, stakeholder marketing and social marketing to the higher ed context."

Enrollment marketers face the difficult task of not only reaching the right audiences but also ensuring each entering class has met specific academic profile goals. And while branding, reputation, and prestige are important elements, maximizing marketing effectiveness is critical when it comes to prospective student recruitment. Similarly, enrollment marketers must navigate a highly complex media environment to reach prospective students. As media environments become more fragmented and cluttered, the management of messaging across consumer touchpoint becomes more important. Aside from fragmentation and clutter, audience multitasking, path to purchase, and media behavior have created the need to enhance IMC (integrated marketing communications) planning to improve marketing outcomes throughout the marketing funnel.

There is a gap in the higher education marketing literature that emphasizes improving enrollment marketing communication strategies through the use of IMC. IMC and cross-channel synergieswhat is produced when the integration of marketing communications is considered - are broad marketing concepts that are worth applying to higher ed outcomes, more specifically enrollment marketing practices.

This article seeks to cull relevant academic research that examines cross-channel synergies and how those synergies make IMC plans more effective. With a better understanding of how synergy is created and how consumer behavior is influenced by the interaction of

\footnotetext{
${ }^{1}$ Grawe, Nathan. Demographics and the Demand for Higher Education. Baltimore, MD: John Hopkins University Press, 2018.

${ }^{2}$ Chapleo, Chris and Helen O'Sullivan. 2017. “Contemporary thought in higher education marketing. Journal of Marketing for Higher Education 27 (2): 159-161.
}

(C) 2020 Christopher Huebner, MMC, M Ed.

This open access article is licensed under a Creative Commons Attribution: Non-Commercial license. DOI: JMCHE/v1i302 
communications, enrollment marketers can develop more effective marketing and recruitment campaigns.

The article is organized as follows. First, a brief examination of marketing in higher education, the history of IMC and how IMC is applied to higher ed. Second, the article will review academic literature on IMC as well as media interaction effects. Finally, the article will take findings that apply to higher education and enrollment management marketing and provide a series of related implications for practitioners.

\section{Marketing in Higher Ed}

Over the past decade, resistance to marketing practice in higher education has dissolved. ${ }^{3}$ Global increase in demand for higher education, student consumerism, shifts in funding and increased competition from for-profit institutions have forced universities to adopt commercial practices. ${ }^{4}$ A recent UPCEA and Helix Education survey revealed that marketing departments spend an average of $\$ 1,037,651$ on marketing expenses. ${ }^{5}$ According to Educational Marketing Group, paid advertising reached $\$ 1.65$ billion in $2016 .{ }^{6}$ What was once considered taboo has now become fully-embraced by most institutions.

\section{Integrated Marketing Communications}

The need to produce "one basic communication strategy for each major target audience" was a reaction to dramatic changes in marketing due to the evolution of mass media environments. ${ }^{7}$ While the practice may have emerged prior, integrated marketing communications (IMC) gained recognition in the 1990s with Schultz, Tannenbaum and Lauterborn's seminal text, Integrated marketing communications: Pulling it together and making it work. Changes in the consumer and expanding media environment further led to the need to create a customer-centric, unified approach across an array of marketing communication channels. ${ }^{8}$

What hasn't been agreed upon is the "semantically different aspects of IMC." "For some, IMC refers to the development of a system that manages the long-term relationship with consumers

\footnotetext{
${ }^{3}$ Edmiston-Strasser, Dawn M. 2009. “An Examination of Integrated Marketing Communication in U.S. Public Institutions of Higher Education." Journal of Marketing for Higher Education 19 (2): 142-165.

${ }^{4}$ Canterbury, Richard M. 1999. "Higher Education Marketing: A Challenge.” Journal of Marketing for Higher Education. 9(3). 15-23.

${ }^{5}$ UPCEA. 2018. "Media Expenditures Budgeting Among Higher Education Providers." https://upcea.edu/mediaexpenditures-budgeting-among-higher-education-providers/

${ }^{6}$ Brock, Bob. 2017. "Brand Bounce.” Educational Marketing Group. https://emgonline.com/2017/10/collegeadvertising-at-all-time-high/

${ }^{7}$ Duncan, T. R. and Everett, S. E. 1993. "Client Perceptions of Integrated Marketing Communications. Journal of Advertising Research. 33 (1): 30-38.

${ }^{8}$ Schultz, Don E, Stanley I. Tannenbaum and Robert F. Lauterborn. 1993. Integrated Marketing Communications: Pulling it together and making it work. Illinois: NTC Publishing Group.

${ }^{9}$ Furtado, Karishma and Sarah Moore. 2014. Developing and Executing an Integrated Marketing Campaign. Education Advisory Board.
}

(C) 2020 Christopher Huebner, MMC, M Ed.

This open access article is licensed under a Creative Commons Attribution: Non-Commercial license. DOI: JMCHE/v1i302 


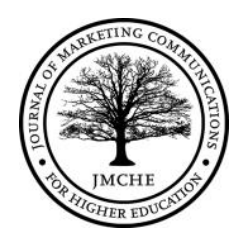

and other stakeholders. ${ }^{10}$ Integration can also refer to an organizational process. This aspect refers to the organizational processes that promote or inhibit the alignment of communication activities. ${ }^{11}$ A final aspect of IMC refers to the integration of content and the consistency of the marketing communications mix to improve brand measures. ${ }^{1213}$ Marketing academics tend to place more of an emphasis on the outcomes of IMC. Thus, IMC becomes the optimal design of marketing communication programs, based on consumer-driven outcomes. ${ }^{14}$ To this end, Naik and Raman defined IMC as "an IMC program plans and executes various marketing activities with consistency so that its total impact exceeds the sum of each activity's impact." 15

IMC that seeks to develop the optimal design of marketing communications programs, concerns itself with how media interact and each how each medium contributes to the overall effect of the campaign. ${ }^{16}$ Within this context, both marketing and advertising literature examine ways to strengthen integrated marketing communications through cross-channel synergies, cross-media effects and cross-platform effects. ${ }^{17}$

If the goal of IMC is the coordination and integration of the promotional mix, then understanding the ways integration can occur - via functional integration, message integration, media integration, integration of timing or creative integration - is important to further optimize an integrated marketing campaign's impact. In the following section, these types of media integrations will be explored further.

\section{Integrated Marketing Communications in Higher Ed}

The first mention of integrated marketing communications in the Journal of Marketing for Higher Education was in 1988, one of the journal's first volumes. In An Integrated Marketing Effort: How It Is Implemented, Miklich called on institutions of higher education to implement integrated marketing to strengthen the promotion of the university. ${ }^{18}$ Subsequent studies

\footnotetext{
${ }^{10}$ Duncan, Thomas R. 2002. IMC: Using Advertising and Promotion to Build Brands. New York: The McGraw-Hill Companies, INC.

${ }^{11}$ Eagle, Lynne and Philip J. Kitchen. 2000. "IMC, Brand Communications, and Corporate Cultures:

Client/Advertising Agency Co-ordination and Cohesion.” European Journal of Marketing 34 (5/6): 667-686.

${ }^{12}$ Schultz, Don E. 1993a. "Integrated Marketing Communications: Maybe Definition Is in the Point of View." Marketing News. January

${ }^{13}$ Schultz, Don E. 1993b. "IMC Has Become a Global Concept. Marketing News. 30 (5).

${ }^{14}$ Batra, Rajeev and Keven L. Keller. 2016. "Integrated Marketing Communications: New Findings, New Lessons, and New Ideas.” Journal of Marketing. 80 (Nov.): 122-145.

${ }^{15}$ Naik, P. A. and Raman, K. 2003. "Understanding the Impact of Synergy in Multimedia Communications.” Journal of Marketing Research 40 (4): 375-388.

${ }^{16}$ Voorveld, H. A. M., Neijens, P. C. \& Smit, E. G. 2012. "The Interacting Role of Media Sequence and Product Involvement in Cross-Media Campaigns." Journal of Marketing Communications 18 (3): 203-216.

${ }^{17}$ Assael, Henry. (2011). "From Silos to Synergy: A Fifty-year Review of Cross-media Research Shows Synergy Has Yet to Achieve its Full Potential." Journal of Advertising Research 51 (1): 42-58.

${ }^{18}$ Miklich, Beverly A. 1988. “An Integrated Marketing Effort: How It Is Implemented.” Journal of Marketing for Higher Education 1 (1): 15-29.
}

(C) 2020 Christopher Huebner, MMC, M Ed.

This open access article is licensed under a Creative Commons Attribution: Non-Commercial license.

DOI: JMCHE/v1i302 


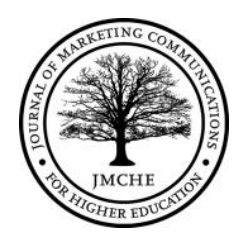

primarily focused on the organizational process of IMC or were produced via third-party vendors or consultancies providing IMC planning guidelines. ${ }^{19202122232425}$

In this context, there is little academic research that specifically looks at how IMC improves higher education marketing outcomes. Smedescu et al. analyzed the appropriate marketing mix for institutions of higher education. ${ }^{26}$ Quinn showed how for-profit IMC practices could be applied to an institution's annual giving campaign. ${ }^{27}$ In an effort to better understand how media fragmentation affects information seeking, Lehne and Rummele showed that IMC could produce cross-media synergies that increased perceived credibility. ${ }^{28}$

\section{Integrated Marketing Effects: Cross-Channel Synergy}

One of the many aspects connected to the concept of IMC is the use and coordination of multiple media in one campaign. Through the use of multiple media, marketers seek to maximize effectiveness by exploiting the unique strengths of each medium and how each subsequent media exposure may influence the impact of the overall campaign. These effects, related to the integration of media, are referred to as cross-channel synergy, cross-platform synergy or crossmedia effects - primarily focusing on interactivity between media and not in relation to a "main" media. $^{29}$

\footnotetext{
${ }^{19}$ Edmiston-Strasser, Dawn M. 2009. “An Examination of Integrated Marketing Communication in U.S. Public Institutions of Higher Education." Journal of Marketing for Higher Education 19 (2): 142-165.

${ }^{20}$ Chang, Yuhmiin, and Esther Thorson. 2004. "Television and Web Advertising Synergies." Journal of Advertising 33 (2): 75-84.

${ }^{21}$ De Diemar, Jeanette. 2016. "Creating an in-house integrated marketing and communications strategy. Journal of Education Advancement \& Marketing 1 (3): 261-271.

${ }^{22}$ Foroudi, Pantea, Keith Dinnie, Philip J. Kitchen, T. C. Melewar and Mohammad M. Foroudi. 2017. "IMC antecedents and the consequences of planned brand identity in higher education." European Journal of Marketing 51 (3): 528-550.

${ }^{23}$ Pavenkov, Oleg V. and Mariia V. Rubtcova. 2019. Use of Integrated Marketing Communications In Promotion Of Higher Education Institution in Russia. International Conference on Sustainable Development ICSD 2019. 14-15 February

${ }^{24}$ Sevier, Robert. 2003. "Integrated Marketing Workbook for Colleges and Universities: A Sept-by-Step Planning Guide." Strategy Publishing.

${ }^{25}$ Furtado, Karishma and Sarah Moore. 2014. Developing and Executing an Integrated Marketing Campaign. Education Advisory Board.

${ }^{26}$ Smedesco, D. A., Ivanov, A. E., Ioanas, E. and Fruth, A. 2016. "Marketing Communications Mix in Higher Education Institutions." International Journal of Academic Research in Economics and Management Science. 5 (4): 291-298.

${ }^{27}$ Quinn, Stephanie M. 2016. "Integrated marketing for annual giving." Journal of Education Advancement \& Marketing 1 (3): 280-286.

${ }^{28}$ Lehne, Margarette and Klaus Rummele. 2016. “Applying a cross-media strategy: How to match diverse information needs with user communication preferences. Journal of Education Advancement \& Marketing 1 (3): 245-260.

${ }^{29}$ Assael, Henry. (2011). "From Silos to Synergy: A Fifty-year Review of Cross-media Research Shows Synergy Has Yet to Achieve its Full Potential." Journal of Advertising Research 51 (1): 42-58.
} 


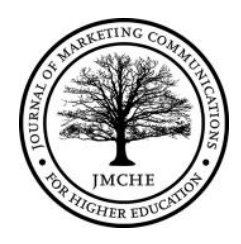

Cross-media research is nothing new, however, with the proliferation of media fragmentation the emphasis has shifted from examining intra-media synergy to inter-media synergy. ${ }^{30}$ Similarly, with the increasing number of channels marketers must consider paired with budgetary constraints, understanding how to maximize the interactive effects of media activities on attention, behavior, and sales is important.

For a review of current literature, the researcher analyzed academic articles on cross-channel synergy using four of the major advertising journals: Journal of Advertising, Journal of Advertising Research, International Journal of Advertising Research and Journal of Marketing Research as well as extant literature found within article citations.

Guided by Neijens and Voorveld, four themes emerge as to the reasons why multimedia campaigns are more effective. ${ }^{31}$

\section{Audience Reach}

Campaigns that use multiple media can reach a larger part of the total audience or improve targeting efficiencies. ${ }^{32333435}$

\section{Complementary Media Effects}

As it relates the strength of each medium, the combined strengths of multiple media complement each other. ${ }^{3637}$

\footnotetext{
${ }^{30}$ Assael, Henry. (2011). "From Silos to Synergy: A Fifty-year Review of Cross-media Research Shows Synergy Has Yet to Achieve its Full Potential." Journal of Advertising Research 51 (1): 42-58.

${ }^{31}$ Neijens, Peter, and Hilde Voorveld. 2015. "Cross-Platform Advertising: Current Practices and Issues for the Future." Journal of Advertising Research 55 (4): 362-67.

${ }^{32}$ Briggs, Rex, R. Krishnan and Norm Borin. 2005. Integrated Multichannel Communication Strategies: Evaluating the Return on Marketing Objectives-The Case of the 2004 Ford F-150 Launch." Journal of Interactive Marketing 19 (3). 81-90.

${ }^{33}$ Ehrenberg-Bass Institute of Marketing Science. 2012. "Planning For Synergy: Harnessing the Power of MultiPlatform Media. Adelaide, Australia: University of South Australia.

${ }^{34}$ Romaniuk, Jenni. 2012. "Five Steps to Smarter Targeting." Journal of Advertising Research 52(3): $288-290$.

${ }^{35}$ Romaniuk, Jenni., Virginia Beal and Mark Uncles. 2013. "Achieving Reach in a Multimedia Environment: How a Marketer's First Step Provides the Direction for the Second.” Journal of Advertising Research 53 (2): $221-228$. ${ }^{36}$ Dijkstra, Majorie, Heidi E. J. J. M. Buitjtels and W. Fred Van Raaij. 2005. "Separate and join effects of medium type on consumer responses: A comparison of television, print, and the internet." Journal of Business Research 58: 377-386.

${ }^{37}$ Okazaki, Shintaro and Morikazu Hirose. 2009. "Effects of Displacement-Reinforcement Between Traditional Media, PC Internet and Mobile Internet: A Quasi-Experiment in Japan.” International Journal of Advertising 28 (1): 77-104.
} 
Vol 1 Issue 3 (2020)

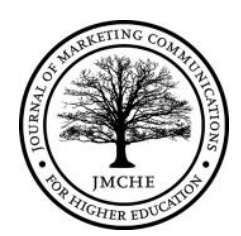

\section{Repetition}

Wear-out can be reduced through varying the media in which ad or message is presented. ${ }^{383940}$

\section{Synergy}

Media in multiple channels within a campaign can "exceed the sum of their individual parts." 41 The literature also examines the underlying psychological processes that influence the synergy between media. Guided by Voorveld, Neijens and Smit, five processes that help to explain why cross-media campaigns produce more positive campaign results are described below. ${ }^{42}$

\section{Forward Encoding}

Forward encoding describes the process of the first advertising exposure "priming" the consumer's interest for and attention to an ad or message in a second medium. According to Keller, when consumers see an ad for the first time, an "ad memory trace" is stored. ${ }^{43}$ Processing at a deeper level is more likely when the second exposure is presented in a different medium, because the first exposure elicited an emotional response or evoked curiosity. ${ }^{44}$ Evidence suggests that when consumers are exposed to the same ad within the same medium, cutting through and gaining attention is less likely. ${ }^{454647}$

\section{Multiple Source Perception}

An advertising message is perceived to be more credible and persuasive when presented across multiple media. Underlying this process is the belief that messages in different media are

\footnotetext{
${ }^{38}$ Stammerjohan, Claire, Charles M. Wood, Yuhmiin Chang and Esther Thorson. 2005. “An Empirical Investigation of the Interaction Between Publicity, Advertising, and Previous Brand Attitudes and Knowledge." Journal of Advertising. 34 (4): 55-67.

${ }^{39}$ Navarro-Bailón, MaríaÁngeles. 2012. "Strategic Consistent Messages in Cross-Tool Campaigns: Effects on Brand Image and Brand Attitude.” Journal of Marketing Communications 18 (3): 189-202.

${ }^{40}$ Kim, Nam Y. (2018). "The Effect of Ad Customization and Ad Variation on Internet Users' Perceptions of Forced Multiple Advertising Exposures and Attitudes.” Journal of Interactive Advertising. 18(1). 15-27.

${ }^{41}$ Neijens, Peter, and Hilde Voorveld. 2015. "Cross-Platform Advertising: Current Practices and Issues for the Future." Journal of Advertising Research 55 (4): 362-67.

${ }^{42}$ Voorveld, Hilde A. M., Peter C. Neijens and Edith G. Smit. 2012. "The Interacting Role of Media Sequence and Product Involvement in Cross-Media Campaigns." Journal of Marketing Communications 18 (3): 203-216.

${ }^{43}$ Keller, Kevin L. 1987. "Memory factors in advertising: The effect of advertising retrieval cues on brand evaluations." Journal of Consumer Research. 14: 316-333.

${ }^{44}$ Steele, Audrey, Devra Jacobs, Caleb Siefert, Randall Rule, Brain Levine and Carl D. Marci. 2013. "Leveraging Synergy and Emotion in a Multi-Platform World: A Neuroscience-Informed Model of Engagement." Journal of Advertising Research 53(4): 417-430.

${ }^{45}$ Edell, Judith A. and Kevin L. Keller. 1989. "The information processing of coordinated media campaigns." Journal of Marketing Research 26: 149-163.

${ }^{46}$ Dijkstra, Majorie. 2002. "An experimental investigation of synergy effects in multiple-media advertising campaigns." Dissertation. Universiteit of Tilburg, The Netherlands.

${ }^{47}$ Voorveld, Hilde A. M., Peter C. Neijens and Edith G. Smit. 2012. "The Interacting Role of Media Sequence and Product Involvement in Cross-Media Campaigns.” Journal of Marketing Communications 18 (3): 203-216.
}

(C) 2020 Christopher Huebner, MMC, M Ed.

This open access article is licensed under a Creative Commons Attribution: Non-Commercial license. DOI: JMCHE/v1i302 


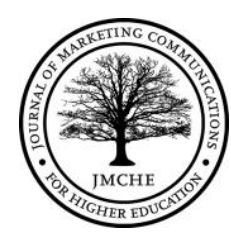

believed to be from independent sources. ${ }^{4849505152}$ Likewise, repetition is seen as costly by consumers. Nelson's economic signaling theory would indicate that consumers see advertising repetition as an indication of the firm's confidence in its product. ${ }^{53}$

\section{Image Transfer}

Image transfer occurs when consumers imagine or retrieve specific cues from a previously viewed ad during the second exposure of the ad. Marketing academics argue that consumer memory is improved when cues encoded during first exposure are present at retrieval (ad or point of purchase). ${ }^{54}$ Retrieval cues are branding activities like slogans, logos, repeated visuals or design elements and celebrity endorsers. Researchers posit that image transfer may be stronger when consumers are exposed to a combination of media verses repeatedly exposed to the same message in the same medium. ${ }^{55}$

\section{Encoding Variability}

In comparison to single-media campaigns, similar messages presented in separate media will be encoded differently, developing a broader, more complex memory network. ${ }^{565758}$

\section{Elaboration Likelihood Model}

Consumers who are exposed to a multimedia campaign form their attitudes through central processing, whereas consumers exposed to a message in a single medium form their attitudes

\footnotetext{
${ }^{48}$ Dijkstra, M. 2002. “An experimental investigation of synergy effects in multiple-media advertising campaigns." Dissertation. Universiteit of Tilburg, The Netherlands.

${ }^{49}$ Chang, Yuhmiin, and Esther Thorson. 2004. "Television and Web Advertising Synergies." Journal of Advertising 33 (2): 75-84.

${ }^{50}$ Voorveld, Hilde A. M., Peter C. Neijens and Edith G. Smit. 2012. "The Interacting Role of Media Sequence and Product Involvement in Cross-Media Campaigns.” Journal of Marketing Communications 18 (3): 203-216.

${ }^{51}$ Laroche, Michel, Isar Kiani, Nectarios Economakis, and Marie-Odile Richard. 2013. "Effects of Multi-Channel Marketing on Consumers' Online Search Behavior: The Power of Multiple Points of Connection." Journal of Advertising Research 53 (4): 431-43

${ }^{52}$ Kumar. Ashish, Ram Bezawada, Rishika Rishika, Ramkumar Janakiraman and P. K. Kannan. (2016). "From Social to Sale: The Effects of Firm-Generated Content in Social Media on Customer Behavior." Journal of Marketing. 80 (1). 7-25.

${ }^{53}$ Nelson. Phillip. 1974. “Advertising as information. Journal of Political Economy. 82: 729-754.

${ }^{54}$ Voorveld, H. A. M. and Sanne M. F. Valkenburg. 2015. "The Fit Factor: The Role of Fit Between Ads in Understanding Cross-Media Synergy." Journal of Advertising 44 (3): 185-195.

${ }^{55}$ Dijkstra, M. 2002. "An experimental investigation of synergy effects in multiple-media advertising campaigns." Dissertation. Universiteit of Tilburg, The Netherlands.

${ }^{56}$ Ehrenberg-Bass Institute of Marketing Science. 2012. "Planning For Synergy: Harnessing the Power of MultiPlatform Media. Adelaide, Australia: University of South Australia.

${ }^{57}$ Vandeberg, Lisa. Jaap M. J. Murre, Hilde A. M. Voorveld and Edith G. Smit. 2015. "Dissociating explicit and implicit effects of cross-media advertising." International Journal of Advertising. 34 (5). 744-764.

${ }^{58}$ Voorveld, H. A. M. and Sanne M. F. Valkenburg. 2015. "The Fit Factor: The Role of Fit Between Ads in Understanding Cross-Media Synergy." Journal of Advertising 44 (3): 185-195.
}

(C) 2020 Christopher Huebner, MMC, M Ed.

This open access article is licensed under a Creative Commons Attribution: Non-Commercial license.

DOI: JMCHE/v1i302 


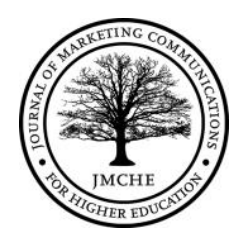

through the peripheral route. ${ }^{596061}$ The central processing is important because it employs a higher level of "thoughtfulness." 62

Taken together, the proposed reasons for IMC campaigns success and the processes that influence multimedia synergy provide strategic insight into effective IMC campaign planning. Using the studies above, the next section will define key themes to help enrollment management marketers plan and optimize IMC activities.

\section{Cross-Channel Synergy: Outcomes and How To Maximize Them}

In the Journal of Marketing Research, Naik and Raman (2003) wrote:

"Integrated marketing communications emphasize the benefits of harnessing synergy across multiple media to build brand equity... The added value aspect of IMC is created by the joint impact of multiple activities (e.g. television and print advertisements) ...In other words, the combined effect of multiple activities exceeds the sum of their individual parts."

The findings in this section describe the academic research that has given practitioners insight into making marketing activities greater than the sum of each "individual part." The author will take themes found in the academic literature and provide implications for enrollment marketers.

\section{Digital Advertising and Search Behavior}

Research indicates that there is cross-channel synergy between digital and search advertising. Not only does digital advertising drive search within a category (and generic category search terms), but it has been shown to generate a greater average lift in brand-related searches. ${ }^{646566}$

\footnotetext{
${ }^{59}$ Petty, Richard E. and John T. Cacioppo. 1996. Attitudes and Persuasion: Classic and Contemporary Approaches. Boulder, CO: Westview Press.

${ }^{60}$ Chang, Yuhmiin, and Esther Thorson. 2004. "Television and Web Advertising Synergies." Journal of Advertising 33 (2): 75-84.

${ }^{61}$ Heath, Robert. 2006. "Emotional persuasion.” Admap. 46-48.

${ }^{62}$ ibid

${ }^{63}$ Naik, Prasad A. and Kalyan Raman. 2003. "Understanding the Impact of Synergy in Multimedia

Communications." Journal of Marketing Research 40 (4): 375-388.

${ }^{64}$ Google \& comScore. 20016. "ComScore Press Release Study Confirms the Importance of Search in influencing Offline buying." comScore. http://www.comscore.com/press/release.asp?press=796

${ }^{65}$ Laroche, Michel, Isar Kiani, Nectarios Economakis, and Marie-Odile Richard. 2013. "Effects of Multi-Channel Marketing on Consumers' Online Search Behavior: The Power of Multiple Points of Connection." Journal of Advertising Research 53 (4): 431-43

${ }^{66}$ Fulgoni, Gian M., and Andrew Lipsman. 2014. "Digital Game Changers: How Social Media Will Help Usher in The Era of Mobile and Multi-Platform Campaign-Effectiveness Measurement." Journal of Advertising Research 54 (1): 11-16.
} 


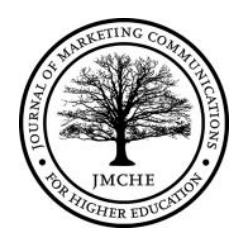

Laroche et al. found that search driven by digital advertising occurred more frequently in the short-term. ${ }^{67}$

Examining social media advertising's effect on search, research indicates that initial exposure on social media may prime the target audience, and with subsequent exposures via other channels, drive message comprehension when creative strategies align across campaigns as well as increase search behavior. ${ }^{686970}$

In both cases, there's an opportunity beyond direct-response to leverage paid and search advertising. Direct-response aside, advertising that seeks to align with other marketing activities can be used to drive search as well as deliver emotional impact prior to search behavior. For example, cutting through social media clutter versus reinforcing consumer search behavior may require different appeals and creative. ${ }^{71}$ Similarly, media environment and consumer behavior are different depending on audience motivations. Search is often driven by information-seeking behavior, while social media offers passive entertainment. Understanding both media context, audience motivations, and cross-channel synergy can help enrollment marketers deliver campaigns that both reinforce desired outcomes, strengthen quality of inquiry and improve effectiveness. $^{727374}$

\section{Implications:}

Instead of using digital advertising as the primary direct response tactic, digital advertising can be used to drive response across other media (search, email, etc). For example, well-branded digital advertising can be used to increase the propensity that a user may open a subsequent

\footnotetext{
${ }^{67}$ Laroche, Michel, Isar Kiani, Nectarios Economakis, and Marie-Odile Richard. 2013. "Effects of Multi-Channel Marketing on Consumers' Online Search Behavior: The Power of Multiple Points of Connection." Journal of Advertising Research 53 (4): 431-43

${ }^{68}$ ibid

${ }^{69}$ Snyder, Jasper, and Manuel Garcia-Garcia. 2016. "Advertising across Platforms: Conditions for Multimedia Campaigns.” Journal of Advertising Research 56 (4): 352-67.

${ }^{70}$ Okadar, Gabrijela. 2017. "How Frequency of Exposure Can Maximize The Resonance of Your Digital Campaigns. The Nielsen Company. https://www.nielsen.com/au/en/insights/article/2017/how-frequency-of-exposure-canmaximise-the-resonance-of-your-digital-campaigns/

${ }^{71}$ Grigaliunaite, Viktorija and Lina Pileliene. 2016. "Emotional or Rational? The Determination of the Influence of Advertising Appeal on Advertising Effectiveness." Scientific Annals of Economics and Business. 63(3): 391-414.

${ }^{72}$ Pashkevich, Max, Sundar Dorai-Raj, Melanie Keller and Dan Zigmond. 2012. "Empowering Online

Advertisements by Empowering Viewers with the Right to Choose: The Relative Effectiveness of Skippable Video Advertisements on YouTube." Journal of Advertising Research. 451-457.

${ }^{73}$ Kim, Nam Y. (2018). "The Effect of Ad Customization and Ad Variation on Internet Users' Perceptions of Forced Multiple Advertising Exposures and Attitudes." Journal of Interactive Advertising. 18(1). 15-27.

${ }^{74}$ Kwon, Eun S, Karen W. King, Greg Nyilsay and Leonard N. Reid. 2019. "Impact of Media Context on Advertising Memory: A Meta-Analysis of Advertising Effectiveness.” Journal of Advertising Research. 99-128.
}

(C) 2020 Christopher Huebner, MMC, M Ed.

This open access article is licensed under a Creative Commons Attribution: Non-Commercial license.

DOI: JMCHE/v1i302 


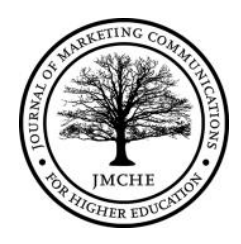

email or direct-response mailer. In fact, high-quality and well-branded digital advertising may have more of an impact on indirect effects versus measurable conversions. ${ }^{75}$

Optimize search for "brand" in the short term and category throughout duration of campaign or as campaign evolves. Increasing digital advertising spend does not necessarily produce more search queries. In most cases, the elasticity was greatest within the first three weeks. Depending on budget — as brand terms see diminished returns - category terms can continue to be optimized, especially as enrollment marketers hit milestones within college search (standardized tests, tour season, recruitment events). ${ }^{76}$

Appealing to both the head and the heart can evolve across channels or throughout the campaign. Not only are consumers engaging with content differently across channels, but their motivations differ, as well. Competing for attention in social media with messages that push informationdriven messaging (visit, cost, deadlines) may not cut through. Advertising research suggests that emotion-driven messaging works much better in low-involvement environments, like social media. ${ }^{77}$ Using search as an opportunity to deliver those information-driven appeals, when prospective students are motivated and actively seek-information can strengthen communications outcomes. $^{78}$

\section{Priming Effects Drive Brand Outcomes}

In the Advertised Mind, Erik du Plessis wrote, "Emotion in advertising is important in getting our attention. And what we pay attention to gets remembered. And what we have paid attention to and remember in the past, makes us more likely to pay attention to in the future." 79

Priming consumers in one medium can enhance the impact of each additional exposure in a separate medium. For example, emotion-driven ads may act as an important primer for information-based (rational) ads or messaging throughout lower parts of the funnel. ${ }^{8081}$ This may be an important strategy in high-involvement categories or longer customer journeys. Varying

\footnotetext{
${ }^{75}$ Vandeberg, Lisa. Jaap M. J. Murre, Hilde A. M. Voorveld and Edith G. Smit. 2015. "Dissociating explicit and implicit effects of cross-media advertising." International Journal of Advertising. 34 (5). 744-764.

${ }^{76}$ Snyder, Jasper, and Manuel Garcia-Garcia. 2016. “Advertising across Platforms: Conditions for Multimedia Campaigns." Journal of Advertising Research 56 (4): 352-67.

${ }^{77}$ Health, Robert and Nairn, Agnes. 2005. "Measuring Emotive Advertising-Implications of Low Attention Processing on Recall. Journal of Advertising Research. 45(2). 269-281.

${ }^{78}$ Burton, Jennifer Lee, Jan Gollins, Linda E. McNeely, and Danielle M. Walls. 2019. "Revisiting the Relationship between Ad Frequency and Purchase Intentions: How Affect and Cognition Mediate Outcomes At Different Levels of Advertising Frequency." Journal of Advertising Research 59 (1): 27-39.

${ }^{79}$ Du Plessis, Erik. 2005. "The Advertised Mind.” New York, NY: Kogan Page Business Books.

${ }^{80}$ Nelson-Field, Karen. 2017. "Does Emotional Advertising Aid Advertising Effectiveness.” ThinkTV's The Benchmark Series.

${ }^{81}$ Burton, Jennifer Lee, Jan Gollins9, Linda E. McNeely, and Danielle M. Walls. 2019. "Revisiting the Relationship between Ad Frequency and Purchase Intentions: How Affect and Cognition Mediate Outcomes At Different Levels of Advertising Frequency." Journal of Advertising Research 59 (1): 27-39.
}

(C) 2020 Christopher Huebner, MMC, M Ed.

This open access article is licensed under a Creative Commons Attribution: Non-Commercial license. DOI: JMCHE/v1i302 


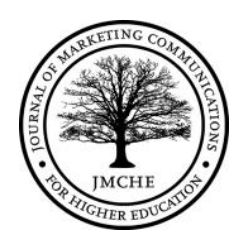

messaging type - emotion-driven and information-driven — can reduce intrusiveness and lead to positive brand attitudes over the course of a campaign. ${ }^{8283}$

\section{Implications}

Higher-level marketing activities should seek to create an emotional appeal driven by what brings prospective students to category or consideration set. Ultimately, the tactic should trigger the problem-recognition phase of the decision-making process. In most cases, print publications, web assets and email can provide proof points that reinforce an emotional response. ${ }^{8485}$

Consumer often post-rationalize consumption behavior, thus, facts and functional benefits help reinforce a consumer's emotional response or act as a motivator for consumption-related goals, an important finding when prospective students have moved from establishing fit to considering reality of cost. 8687

\section{Paid and Owned Assets Have Synergy}

In consumer goods, "firm-generated content" has shown to have a positive impact on customer spending and cross-buying. ${ }^{8889}$ Among marketing tactics, television and email marketing are seen to have the greatest synergistic effects. In some cases, social media has been shown to contribute to building brand equity, by reinforcing key brand narratives and associations by aligning messaging. ${ }^{9091}$

\section{Implications:}

Digital advertising and email marketing campaigns drive traffic to social media. While social media strategy may be laid out months in advance, message synergy between paid and organic content is vastly important. Marketers should ask if the most current organic content on brand's

\footnotetext{
${ }^{82}$ Yaveroglu, Idil and Navenn Donthu. 2008. “Advertising Repetition and Placement Issues in On-line Environments." Journal of Advertising Research. 37(2). 31-43.

${ }^{83}$ Kim, Nam Y. (2018). "The Effect of Ad Customization and Ad Variation on Internet Users' Perceptions of Forced Multiple Advertising Exposures and Attitudes.” Journal of Interactive Advertising. 18(1). 15-27.

${ }^{84}$ Johar, J.S. and M. Joseph Sirgy. (1991), "Value-expressive versus utilitarian advertising appeals: when and why to use which appeal." Journal of Advertising. 20 (3). 23-33.

${ }^{85}$ Health, Robert and Agnes Nairn. 2005. "Measuring Emotive Advertising-Implications of Low Attention Processing on Recall. Journal of Advertising Research. 45(2). 269-281.

${ }^{86}$ Barden, Phil. (2013). Decoded: The Science Behind Why We Buy. Hoboken, NJ: John Wiley \& Sons.

${ }^{87}$ Kantar Millward Brown. 2019. “Advertising: Making a Lasting Impression.” Accessed: http://www.millwardbrown.com/Documents/Reports/Make_a_Lasting_Impression/default.aspx?access=yes

${ }^{88}$ Danaher, Peter J. and Tracey S. Dagger. 2013. "Comparing the Relative Effectiveness of Advertising Channels: A Case Study of a Multimedia Blitz Campaign. Journal of Marketing Research. 50 (Aug.) 517-534.

${ }^{89}$ Kumar. Ashish, Ram Bezawada, Rishika Rishika, Ramkumar Janakiraman and P. K. Kannan. (2016). "From

Social to Sale: The Effects of Firm-Generated Content in Social Media on Customer Behavior." Journal of Marketing. 80 (1). 7-25.

${ }^{90}$ Gensler, Sonja, Franziska Volckner, Yuping Liu-Thompkins and Caroline Wiertz. 2013. "Managing Brands in the Social Media Environment." Journal of Interactive Marketing. 27(4). 242-256.

${ }^{91} \mathrm{Li}$, Hongshuang and P. K. Kannan. (2014). "Attributing Conversions in a Multichannel Online Marketing Environment: An Empirical Model and a Field Experiment,” Journal of Marketing Research, 51 (February), $40-56$.
}

(C) 2020 Christopher Huebner, MMC, M Ed.

This open access article is licensed under a Creative Commons Attribution: Non-Commercial license.

DOI: JMCHE/v1i302 


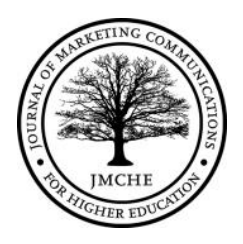

page match or reinforce the brand's current campaign. ${ }^{92}$ As it relates to sales, research would suggest that this lack of synergy is a missed opportunity. ${ }^{9394}$

Similarly, if cross-buying is a product of consumers' trust in known product offering, do institutional offerings - product-like benefits (internships, study abroad, etc.) — produce similar effects? If so, what shows up on an institution's social media page during paid campaigns should consider related benefits and their place within campaign platform or narrative. ${ }^{95}$

\section{Sequence Makes Synergy More Effective}

As stated above, psychological processes related to sequence and variation of media exposure impact marketing effectiveness. Consider both receptivity and recencey (planning message as close to purchase as possible) throughout the buying process or during milestones in decisionmaking to reference or reinforce key moments. ${ }^{96979899}$ As defined by Ephron, receptivity is the "psychological dimensions of response" at the time of ad delivery. Simply put, what a person is thinking, feeling or doing at the time of communication can "greatly enhance" the desired response. ${ }^{100}$

\section{Implications:}

Prospective students will encounter a brand across many touchpoints. Students tour campus, engage with out-of-home media, meet with admissions reps, and the experience the campus environment. Students will also watch athletic events, follow institutions on social media and open recruitment emails. Taking the time to map the customer journey and weigh each touchpoint can establish how - and where - additional communications can be used to enhance a marketer's impact. For example, digital advertising may enhance the positive experience a prospective student had on a campus tour by aligning compelling proof points with the positive emotions felt on tour. ${ }^{101}$

\footnotetext{
${ }^{92}$ Bruhn, Manfred, Verena Schoenmueller and Daniela B. Schafer. (2012), “Are Social Media Replacing Traditional Media in Terms of Brand Equity Creation?” Management Research Review, 35 (9), 770-90.

93 ibid

${ }^{94}$ Kumar. Ashish, Ram Bezawada, Rishika Rishika, Ramkumar Janakiraman and P. K. Kannan. (2016). "From Social to Sale: The Effects of Firm-Generated Content in Social Media on Customer Behavior." Journal of Marketing. 80 (1). 7-25.

${ }^{95}$ Voorveld, Hilde A.M., Peter C. Neijens, and Edith G. Smit. 2011. "Opening the Black Box: Understanding CrossMedia Effects." Journal of Marketing Communications 17 (2): 69-85.

${ }^{96}$ Ephron, Erwin. 1997. "Recency Planning." Journal of Advertising Research. 37(4).

${ }^{97}$ Havlena, William J. and Jeffrey Graham. 2004. "Decay Effects in Online Advertising: Quantifying the Impact of Time Since Last Exposure on Branding Effectiveness." Journal of Advertising Research. 44(4). 327-332.

${ }^{98}$ Vandeberg, Lisa. Jaap M. J. Murre, Hilde A. M. Voorveld and Edith G. Smit. 2015. "Dissociating explicit and implicit effects of cross-media advertising." International Journal of Advertising. 34 (5). 744-764.

${ }^{99}$ Voorveld, H. A. M. and Sanne M. F. Valkenburg. 2015. "The Fit Factor: The Role of Fit Between Ads in Understanding Cross-Media Synergy." Journal of Advertising 44 (3): 185-195.

${ }^{100}$ Ephron, Erwin. 2006. “Media Planning: From Recency to Engagement.” India: DGM Icfai Books.

${ }^{101}$ Steele, Audrey, Devra Jacobs, Caleb Siefert, Randall Rule, Brain Levine and Carl D. Marci. 2013. "Leveraging Synergy and Emotion in a Multi-Platform World: A Neuroscience-Informed Model of Engagement." Journal of Advertising Research 53(4): 417-430.
}

(C) 2020 Christopher Huebner, MMC, M Ed.

This open access article is licensed under a Creative Commons Attribution: Non-Commercial license. DOI: JMCHE/v1i302 


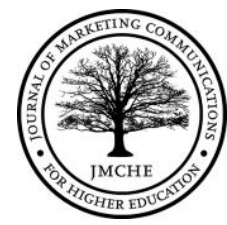

There is no single path to purchase. However, there are patterns in decision making across broad segments. Enrollment marketers should develop established moments when consumers are actively shopping the category and developing a sequence of messages that relate to both category entry points (why/when/how consumers transition into making category purchase) or information-seeking moments (time or seasonal patterns in category shopping). ${ }^{102}$ For example, many prospective students move from establishing fit, prior submitting applications, to establishing product benefits based on cost after they have received their decisions.

\section{Conclusion}

As the higher education marketplace constricts and demographics shift, enrollment management marketers will experience increased competition and enrollment demands. More than ever, enrollment management marketers must navigate complex media environments and the evolving behaviors of prospective students. With or without an increase in marketing budget, the current media environment and increasing consumer touchpoints make developing a cohesive, multimedia communications plan a top priority. Through an analysis of cross-media effects and synergy, the author has given enrollment management marketers a foundation to plan for optimizing both individual communication channels as well as how multiple channels produce synergistic effects. Four cross-channel effects were examined further and implications identified to help enrollment management marketers create more effective, long-term communications plans.

\footnotetext{
${ }^{102}$ Sharp, Byron. How Brands Grow: What Marketers Don't Know. Oxford: Oxford University Press, 2010.
} 
Vol 1 Issue 3 (2020)

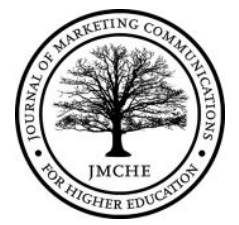

\section{References}

Assael, Henry. (2011). "From Silos to Synergy: A Fifty-year Review of Cross-media Research Shows Synergy Has Yet to Achieve its Full Potential." Journal of Advertising Research 51 (1): 42-58.

Barden, Phil. (2013). Decoded: The Science Behind Why We Buy. Hoboken, NJ: John Wiley \& Sons.

Batra, Rajeev and Keven L. Keller. 2016. "Integrated Marketing Communications: New Findings, New Lessons, and New Ideas.” Journal of Marketing. 80 (Nov.): 122-145.

Briggs, Rex, R. Krishnan and Norm Borin. 2005. Integrated Multichannel Communication Strategies: Evaluating the Return on Marketing Objectives-The Case of the 2004 Ford F-150 Launch.” Journal of Interactive Marketing 19 (3). 81-90.

Brock, Bob. 2017. "Brand Bounce.” Educational Marketing Group. https://emgonline.com/2017/10/college-advertising-at-all-time-high/

Bruhn, Manfred, Verena Schoenmueller and Daniela B. Schafer. (2012), “Are Social Media Replacing Traditional Media in Terms of Brand Equity Creation?" Management Research Review, 35 (9), 770-90.

Burton, Jennifer Lee, Jan Gollins, Linda E. McNeely, and Danielle M. Walls. 2019. "Revisiting the Relationship between Ad Frequency and Purchase Intentions: How Affect and Cognition Mediate Outcomes at Different Levels of Advertising Frequency." Journal of Advertising Research 59 (1): 27-39.

Canterbury, Richard M. 1999. "Higher Education Marketing: A Challenge." Journal of Marketing for Higher Education. 9(3). 15-23.

Casey, Russell and Lauren P. Llewellyn. 2012. "Brand Consistency in Social Media: WVU's Eberly Works Toward a Conceptual Framework of Integrated Marketing Communications." International Journal of Integrated Marketing. 17-26.

Chang, Yuhmiin, and Esther Thorson. 2004. "Television and Web Advertising Synergies." Journal of Advertising 33 (2): 75-84.

Chapleo, Chris and Helen O'Sullivan. 2017. "Contemporary thought in higher education marketing. Journal of Marketing for Higher Education 27 (2): 159-161.

Danaher, Peter J. and Tracey S. Dagger. 2013. "Comparing the Relative Effectiveness of Advertising Channels: A Case Study of a Multimedia Blitz Campaign. Journal of Marketing Research. 50 (Aug.) 517-534.

De Diemar, Jeanette. 2016. "Creating an in-house integrated marketing and communications strategy. Journal of Education Advancement \& Marketing 1 (3): 261-271.

(C) 2020 Christopher Huebner, MMC, M Ed.

This open access article is licensed under a Creative Commons Attribution: Non-Commercial license.

DOI: JMCHE/v1i302 
Du Plessis, Erik. 2005. “The Advertised Mind.” New York, NY: Kogan Page Business Books.

Dijkstra, Majorie. 2002. "An experimental investigation of synergy effects in multiple-media advertising campaigns.” Dissertation. Universiteit of Tilburg, The Netherlands.

Dijkstra, Majorie, Heidi E. J. J. M. Buitjtels and W. Fred Van Raaij. 2005. "Separate and join effects of medium type on consumer responses: A comparison of television, print, and the internet." Journal of Business Research 58: 377-386.

Duncan, Thomas R. 2002. IMC: Using Advertising and Promotion to Build Brands. New York: The McGraw-Hill Companies, INC.

Duncan, Thomas R. and Stephen E. Everett. 1993. "Client Perceptions of Integrated Marketing Communications. Journal of Advertising Research. 33 (1): 30-38.

Eagle, Lynne and Philip J. Kitchen. 2000. "IMC, Brand Communications, and Corporate Cultures: Client/Advertising Agency Co-ordination and Cohesion.” European Journal of Marketing 34 (5/6): 667-686.

Edell, Judith A. and Kevin L. Keller. 1989. "The information processing of coordinated media campaigns." Journal of Marketing Research 26: 149-163.

Edmiston-Strasser, Dawn M. 2009. “An Examination of Integrated Marketing Communication in U.S. Public Institutions of Higher Education.” Journal of Marketing for Higher Education 19 (2): 142-165.

Ehrenberg-Bass Institute of Marketing Science. 2012. "Planning For Synergy: Harnessing the Power of Multi-Platform Media. Adelaide, Australia: University of South Australia.

Ephron, Erwin. 1997. “Recency Planning.” Journal of Advertising Research. 37(4).

Ephron, Erwin. 2006. "Media Planning: From Recency to Engagement.” India: DGM Icfai Books.

Foroudi, Pantea, Keith Dinnie, Philip J. Kitchen, T. C. Melewar and Mohammad M. Foroudi. 2017. "IMC antecedents and the consequences of planned brand identity in higher education." European Journal of Marketing 51 (3): 528-550.

Fulgoni, Gian M., and Andrew Lipsman. 2014. "Digital Game Changers: How Social Media Will Help Usher in The Era of Mobile and Multi-Platform Campaign-Effectiveness Measurement." Journal of Advertising Research 54 (1): 11-16.

Furtado, Karishma and Sarah Moore. 2014. Developing and Executing an Integrated Marketing Campaign. Education Advisory Board. REPORT 


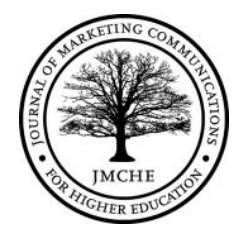

Gensler, Sonja, Franziska Volckner, Yuping Liu-Thompkins and Caroline Wiertz. 2013.

"Managing Brands in the Social Media Environment." Journal of Interactive Marketing. 27(4). 242-256.

Google \& comScore. 2006. "ComScore Press Release Study Confirms the Importance of Search in influencing Offline buying." comScore.

http://www.comscore.com/press/release.asp?press=796

Grawe, Nathan. Demographics and the Demand for Higher Education. Baltimore, MD: John Hopkins University Press, 2018.

Grigaliunaite, Viktorija and Lina Pileliene. 2016. "Emotional or Rational? The Determination of the Influence of Advertising Appeal on Advertising Effectiveness." Scientific Annals of Economics and Business. 63(3): 391-414.

Havlena, William J. and Jeffrey Graham. 2004. "Decay Effects in Online Advertising: Quantifying the Impact of Time Since Last Exposure on Branding Effectiveness." Journal of Advertising Research. 44(4). 327-332.

Heath, Robert. 2006. "Emotional persuasion.” Admap. 46-48.

Health, Robert and Nairn, Agnes. 2005. "Measuring Emotive Advertising-Implications of Low Attention Processing on Recall. Journal of Advertising Research. 45(2). 269-281.

Johar, J.S. and M. Joseph Sirgy. (1991), "Value-expressive versus utilitarian advertising appeals: when and why to use which appeal." Journal of Advertising. 20 (3). 23-33.

Kantar Millward Brown. 2019. “Advertising: Making a Lasting Impression.” Accessed: http://www.millwardbrown.com/Documents/Reports/Make_a_Lasting_Impression/default.aspx? access $=$ yes

Keller, Kevin L. 1987. "Memory factors in advertising: The effect of advertising retrieval cues on brand evaluations." Journal of Consumer Research. 14: 316-333.

Kim, Nam Y. (2018). "The Effect of Ad Customization and Ad Variation on Internet Users' Perceptions of Forced Multiple Advertising Exposures and Attitudes." Journal of Interactive Advertising. 18(1). 15-27.

Kumar. Ashish, Ram Bezawada, Rishika Rishika, Ramkumar Janakiraman and P. K. Kannan. (2016). "From Social to Sale: The Effects of Firm-Generated Content in Social Media on Customer Behavior." Journal of Marketing. 80 (1). 7-25.

Kwon, Eun S, Karen W. King, Greg Nyilsay and Leonard N. Reid. 2019. "Impact of Media Context on Advertising Memory: A Meta-Analysis of Advertising Effectiveness." Journal of Advertising Research. 99-128.

(C) 2020 Christopher Huebner, MMC, M Ed.

This open access article is licensed under a Creative Commons Attribution: Non-Commercial license.

DOI: JMCHE/v1i302 


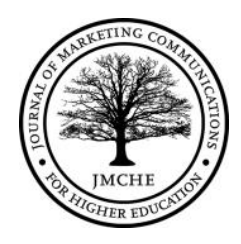

Laroche, Michel, Isar Kiani, Nectarios Economakis, and Marie-Odile Richard. 2013. "Effects of Multi-Channel Marketing on Consumers' Online Search Behavior: The Power of Multiple Points of Connection." Journal of Advertising Research 53 (4): 431-43

Lehne, Margarette and Klaus Rummele. 2016. "Applying a cross-media strategy: How to match diverse information needs with user communication preferences. Journal of Education Advancement \& Marketing 1 (3): 245-260.

Li, Hongshuang and P. K. Kannan. (2014). "Attributing Conversions in a Multichannel Online Marketing Environment: An Empirical Model and a Field Experiment," Journal of Marketing Research, 51 (February), 40-56.

Miklich, Beverly A. 1988. “An Integrated Marketing Effort: How It Is Implemented.” Journal of Marketing for Higher Education 1 (1): 15-29.

Naik, Prasad A. and Kalyan Raman. 2003. "Understanding the Impact of Synergy in Multimedia Communications." Journal of Marketing Research 40 (4): 375-388.

Navarro-Bailón, MaríaÁngeles. 2012. "Strategic Consistent Messages in Cross-Tool Campaigns: Effects on Brand Image and Brand Attitude." Journal of Marketing Communications 18 (3): 189-202.

Neijens, Peter, and Hilde Voorveld. 2015. "Cross-Platform Advertising: Current Practices and Issues for the Future.” Journal of Advertising Research 55 (4): 362-67.

Nelson. Phillip. 1974. “Advertising as information. Journal of Political Economy. 82: 729-754.

Nelson-Field, K. 2017. "Does Emotional Advertising Aid Advertising Effectiveness." ThinkTV's The Benchmark Series.

Okadar, Gabrijela. 2017. "How Frequency of Exposure Can Maximize The Resonance of Your Digital Campaigns. The Nielsen Company. https://www.nielsen.com/au/en/insights/article/2017/how-frequency-of-exposure-can-maximisethe-resonance-of-your-digital-campaigns/

Okazaki, Shintaro and Morikazu Hirose. 2009. "Effects of Displacement-Reinforcement Between Traditional Media, PC Internet and Mobile Internet: A Quasi-Experiment in Japan.” International Journal of Advertising 28 (1): 77-104.

Pashkevich, Max, Sundar Dorai-Raj, Melanie Keller and Dan Zigmond. 2012. "Empowering Online Advertisements by Empowering Viewers with the Right to Choose: The Relative Effectiveness of Skippable Video Advertisements on YouTube.” Journal of Advertising Research. 451-457.

Pavenkov, Oleg V. and Mariia V. Rubtcova. 2019. Use of Integrated Marketing Communications In Promotion Of Higher Education Institution in Russia. International Conference on Sustainable Development ICSD 2019. 14-15 February

(C) 2020 Christopher Huebner, MMC, M Ed.

This open access article is licensed under a Creative Commons Attribution: Non-Commercial license. DOI: JMCHE/v1i302 


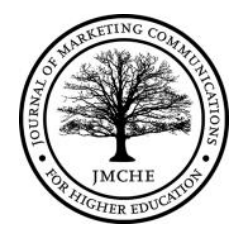

Petty, Richard E. and John T. Cacioppo. 1996. Attitudes and Persuasion: Classic and Contemporary Approaches. Boulder, CO: Westview Press.

Quinn, Stephanie M. 2016. "Integrated marketing for annual giving." Journal of Education Advancement \& Marketing 1 (3): 280-286.

Romaniuk, Jenni. 2012. "Five Steps to Smarter Targeting." Journal of Advertising Research 52(3): 288-290.

Romaniuk, Jenni., Virginia Beal and Mark Uncles. 2013. "Achieving Reach in a Multimedia Environment: How a Marketer's First Step Provides the Direction for the Second." Journal of Advertising Research 53 (2): 221-228.

Schultz, Don E. 1993a. "Integrated Marketing Communications: Maybe Definition Is in the Point of View." Marketing News. January

Schultz, Don E. 1993b. “IMC Has Become a Global Concept. Marketing News. 30 (5).

Schultz, Don E, Stanley I. Tannenbaum and Robert F. Lauterborn. 1993. Integrated Marketing Communications: Pulling it together and making it work. Illinois: NTC Publishing Group.

Sevier, Robert. 2003. "Integrated Marketing Workbook for Colleges and Universities: A Septby-Step Planning Guide." Strategy Publishing.

Sharp, Byron. How Brands Grow: What Marketers Don't Know. Oxford: Oxford University Press, 2010.

Sheehan, Kin B. and Caitlin Doherty. 2001. "Re-weaving the Web: Integrating Print and Online Communications." Journal of Interactive Marketing 15 (2): 47-59.

Smedesco, Dan A., Adelina E. Ivanov, Elisabeta Ioanas, and Andreas Fruth. 2016. "Marketing Communications Mix in Higher Education Institutions." International Journal of Academic Research in Economics and Management Science. 5 (4): 291-298.

Snyder, Jasper, and Manuel Garcia-Garcia. 2016. "Advertising across Platforms: Conditions for Multimedia Campaigns.” Journal of Advertising Research 56 (4): 352-67.

Stammerjohan, Claire, Charles M. Wood, Yuhmiin Chang and Esther Thorson. 2005. "An Empirical Investigation of the Interaction Between Publicity, Advertising, and Previous Brand Attitudes and Knowledge." Journal of Advertising. 34 (4): 55-67.

Steele, Audrey, Devra Jacobs, Caleb Siefert, Randall Rule, Brain Levine and Carl D. Marci. 2013. "Leveraging Synergy and Emotion in a Multi-Platform World: A Neuroscience-Informed Model of Engagement." Journal of Advertising Research 53(4): 417-430.

Taylor, Jennifer, Rachel Kennedy, Colin McDonald, Laurent Larguinat, Yassinne El Ouarzazi, and Nassim Haddad. 2013. "Is the Multi-Platform Whole More Powerful Than Its Separate

(C) 2020 Christopher Huebner, MMC, M Ed.

This open access article is licensed under a Creative Commons Attribution: Non-Commercial license.

DOI: JMCHE/v1i302 
Parts? Measuring the Sales Effects of Cross-Media Advertising." Journal of Advertising Research 53 (2): 200-211.

Tsao, James C. and Stanley D. Sibley. 2004. "Displacement and Reinforcement Effects of the Internet and Other Media Sources of Advertising Information." Journal of Advertising Research 44 (1). 126-142.

UPCEA. 2018. "Media Expenditures Budgeting Among Higher Education Providers." https://upcea.edu/media-expenditures-budgeting-among-higher-education-providers/

Vandeberg, Lisa. Jaap M. J. Murre, Hilde A. M. Voorveld and Edith G. Smit. 2015. "Dissociating explicit and implicit effects of cross-media advertising." International Journal of Advertising. 34 (5). 744-764.

Voorveld, Hilde A.M., Peter C. Neijens, and Edith G. Smit. 2011. "Opening the Black Box: Understanding Cross-Media Effects.” Journal of Marketing Communications 17 (2): 69-85.

Voorveld, Hilde A. M., Peter C. Neijens and Edith G. Smit. 2012. "The Interacting Role of Media Sequence and Product Involvement in Cross-Media Campaigns." Journal of Marketing Communications 18 (3): 203-216.

Voorveld, H. A. M. and Sanne M. F. Valkenburg. 2015. "The Fit Factor: The Role of Fit Between Ads in Understanding Cross-Media Synergy.” Journal of Advertising 44 (3): 185-195.

Voorveld, H. A. M., G. Van Noort. 2014. "Social Media in Advertising Campaigns: Examining the Effects on Perceived Persuasive Intent, Campaign and Brand Responses." Journal of Creative Communications 9 (3): 253-268.

Wakolbinger, Lea M, Michaela Denk and Klaus Oberecker. 2009. "The Effectiveness of Combining Online and Print Advertising: Is the Whole Better Than the Individual Parts?" Journal of Advertising Research 49(3): 360-372.

Yaveroglu, Idil and Navenn Donthu. 2008. "Advertising Repetition and Placement Issues in Online Environments.” Journal of Advertising Research. 37(2). 31-43.

(C) 2020 Christopher Huebner, MMC, M Ed.

This open access article is licensed under a Creative Commons Attribution: Non-Commercial license. DOI: JMCHE/v1i302 